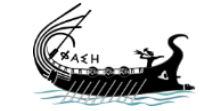

journal.phaselis.org
PHAS LLIS Issue IV (2019)
Disiplinlerarası Akdeniz Araştırmaları Dergisi

Journal of Interdisciplinary Mediterranean Studies

\title{
Kaunos Demeter Kutsal Alanı: Kandiller
}

Kaunos Demeter Sanctuary: Lamps

\section{Mustafa BULBA}

(D) https://orcid.org/ 0000-0002-7034-0575

open Access journals

The entire contents of this journal, Phaselis: Journal of Interdisciplinary Mediterranean Studies, is open to users and it is an 'open access' journal. Users are able to read the full texts, to download, to copy, print and distribute without obtaining the permission of the editor and author(s). However, all references to the articles published in the e-journal Phaselis are to indicate through reference the source of the citation from this journal.

Phaselis: Journal of Interdisciplinary Mediterranean Studies is a peer-reviewed journal and the articles which have had their peer reviewing process completed will be published on the web-site (journal.phaselis.org) in the year of the journal's issue (e.g. Issue IV: JanuaryDecember 2018). At the end of December 2018 the year's issue is completed and Issue V: January-December 2019 will begin.

Responsibility for the articles published in this journal remains with the authors.

Citation M. Bulba, "Kaunos Demeter Kutsal Alanı: Kandiller". Phaselis V (2019) 31-41. http://dx.doi.org/10.18367/Pha.19002

Received Date: 04.01.2019 | Acceptance Date: 12.02.2019

Online Publication Date: 13.02.2019

Editing Phaselis Research Project

www.phaselis.org 


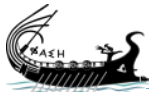

Geliş Tarihi: 04.01.2019

Kabul Tarihi: 12.02 .2019

Yayın Tarihi: 13.02.2019
PHAS LLIS

$\mathrm{V}(2019)$ 31-41

DOI: 10.18367/Pha.19002

journal.phaselis.org

\title{
Kaunos Demeter Kutsal Alanı: Kandiller
}

\author{
Kaunos Demeter Sanctuary: Lamps
}

\author{
Mustafa BULBA*
}

Öz: Khthonik bir özelliğe sahip olduğu anlaşılan Kaunos Demeter Kutsal Alanı'nda yoğun miktarda ele geçen kandiller ile çok nadir olarak ele geçen kandil kernosları Geç Arkaik Dönem'den Olgun Hellenistik Dönem'e kadar olan süreçte adanmışlardır. Diğer buluntulara oranla çok daha yüksek sayıda ele geçmeleri törene katılanların bu minyatür kandilleri severek adadıklarını ve bunların törenlerde önemli bir role sahip olduklarını göstermektedir. Bırakılma amaçları olasııkla öteki dünyadaki ruhların karanlıkta yollarını bulmalarına yardımcı olmaktır. Bazı örneklerde tespit edilen içlerine altın yaprak ya da kemik parçaları ise adayanların beklentilerini güçlendirmede yardımcı bir role sahip olmalıdır.

Anahtar sözcükler: Kandiller, Kernos, Yeraltı Kültü, Demeter

Abstract: The lamps and the cernuses unearthed from the Caunus Demeter Sacred Site, which is known to have a chthonic property, were dedicated to the goddess Demeter from the Late Archaic to the Middle Hellenistic Period. A much higher number than the other finds indicates that those who participated in the ceremony were dedicated to these miniature lamps and had an important role in ceremonies. Their intentions were to help the souls of the other world to find their way in the dark. The gold leaf or bone fragments, which are found in some examples, should help to strengthen the expectations of the dedicators.

Keywords: Lamps, Cernus, Chthonic Cult, Demeter

Kaunos Demeter Kutsal Alanı kentin Küçükkale olarak adlandırılan bölümünde, kente ve limana hakim konumda ve bir yamaç üzerinde yer almaktadır. Kutsal Alan üzerinde yapılan kazı çaışmalarında herhangi bir tapınak izine rastlanmamış olup kutsal alandaki törenlerin açık havada gerçekleştirilmiş olduğu anlaşılmaktadır ${ }^{1}$. Kutsal Alan'ın merkezini, bir anakaya bloğu ile önüne açılmış iki ocak oluşturmaktadır. MÖ VI. yüzyılda olasıııkla Maussollos Dönemi'nde Kutsal Alan'ın yapısında ve işlevinde önemli değişiklikler yapılmış ve en geniş sınırlarına ulaşacak şekilde teras duvarları ile çevrelenmiştir ${ }^{2}$. Teras içerisinde ve dışında yapılan kazılarda yoğun olarak terrakottalar ${ }^{3}$, minyatür hydria, chythralar ve kernoslardan oluşan seramik buluntular ${ }^{4}$ ile özellikle de bu çalışmanın konusu olan kandiller oluşturur. Buluntulara göre alanın kutsallığı yaklaşık olarak Geç

* Doç. Dr., Akdeniz Üniversitesi, Edebiyat Fakültesi, Arkeoloji Bölümü, Antalya. mbulba@akdeniz.edu.tr (D) https://orcid.org/0000-0002-6369-3786

** Bu makalenin konusunu oluşturan çalışmalar TUBiTAK Projesi kapsamında (Proje No: 109K290) yürütülmüş ve yine TUBITAK Yurtdışı Yayın Desteği Projesi kapsamında (2219) hazırlanmıştır.

Bulba, Kaunos Demeter Kutsal Alanı: Kült Uygulamaları (Yayında).

Bulba, Kaunos Demeter Kutsal Alanı: Mimari ve İdentifikasyon (Yayında).

Bulba 2019, Kaunos Demeter Kutsal Alanı: Terrakotta Buluntular, Cedrus 2019, Baskıda.

Bulba 2018, 159-179. 
Arkaik Dönem'den Hellenistik Dönem içlerine kadar devam etmiş olup Roma Dönemi'nde ise önemini kaybederek üzerinde çok düşük düzeyde tapınımın gerçekleştirildiği bir alana dönüşmüş olmalıdır. Bu evreye ait olabilecek sadece az sayıda kandil ve sikke tespit edilmiş, diğer yoğun buluntu gruplarını oluşturan terrakotta figürinler ile hydria ve kernoslara ait buluntu ele geçmemiştir. Bununla birlikte alanın kutsallığının Hristiyanlık dönemine kadar devam ettiği Kaunos'un en erken ve en büyük kilisesinin buraya yapılmasından anlaşılmaktadır ${ }^{5}$.

Kaunos'taki Demeter Terası içinde ve teras duvarının batı dış duvarında yapılan kazılarda karşımıza çıkan tüm buluntu gruplarına ait eserlerin sayıları genel olarak fazladır. Tüm buluntu grupları içerisinde sayıca en büyük yoğunluk ise açık ara kandillere aittir. Sadece sağlam kandillerin sayısı 60.000'in üzerindedir ${ }^{6}$. Kırık olanlar ile teras üzerinde henüz kazılmayan bölümlerde ele geçmesi muhtemel olanlar da düşünüldüğünde sayının 100.000 üzerine çıkması çok güçlü bir olasıııktır. Kandiller gerek yoğunlukları nedeniyle, gerekse arazinin eğiminden ve atılmalarından dolayı kısmen diğer buluntu gruplarıyla karışmış olsa da özellikle orta nefin doğu kısmı ile güney nefin içerisi ile batı teras duvarının dış bölümünde yoğun ve bir arada ele geçmişlerdir (Fig. 1 ve 2). Bunların neredeyse tamamı basit ve özensiz yapılmış minyatür kandillerden oluşmaktadır.

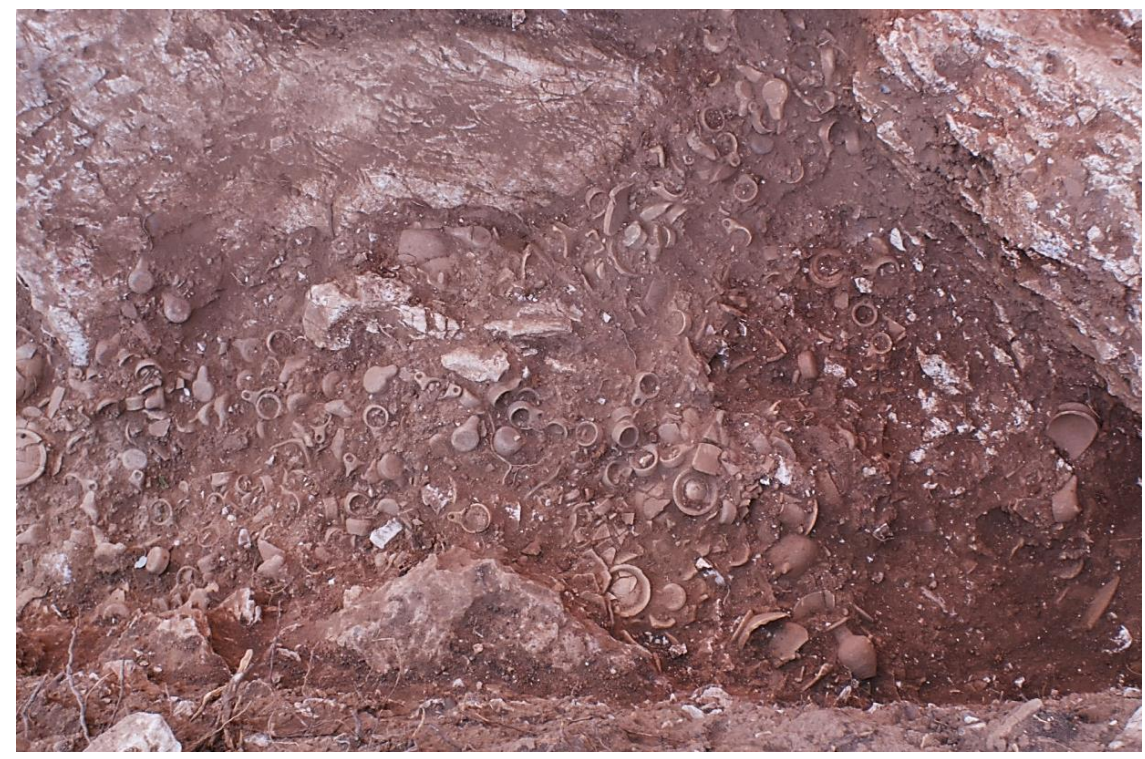

Fig. 1. Demeter Kutsal Alanı. Orta Nef içerisinde ele geçen kandiller

1991 yılından itibaren kurtarma kazıları şeklinde yürütülen kazılardan ele geçen minyatür kandiller B. Varkıvanç tarafından detaylı olarak yayınlanmıştır ${ }^{7}$ (Fig. 3). Minyatür kandillerin tamamı küçük boyutlu olmalarına rağmen tamamı çarkta yapılmışlardır. Kendi içlerinde boyut, gövde ve ağız formları, hamur ve boya renkleri bakımından ayrışmaktadırlar ${ }^{8}$. Kaunos'taki örnekler ortak özellik olarak açık bir gövde biçimine, büyük oranda birbirine yaklaşık gövde cidar kalınlığına

Zäh 2001, 403-413; Zäh 2011/2, 111-116.

6 M. Doyran bir işçiyi görevlendirerek bunları saydırmıştır. Kendisine bu bilgiyi benimle paylaştığı için teşekkür ederim.

7 Varkıvanç 1998, 88-96. Tubitak projesi olarak tarafımdan yürütülen çalışmalarda ele geçen kandillerin form olarak Varkıvanç tarafından yayınlanan eserlerden farklılık göstermemesi nedeniyle bu çalışmada ayrıca bir tipolojik değerlendirme yapılmayacaktır.

8 Varkıvanç 1998, 87-93. Varkıvanç, bu yayını kandil sayısı 16-17.000 civarında iken yapmıştır. 
sahiptirler. Zeminleri tüm örneklerde düz olmayan bir hatta sahiptir ve çark izleri görülmektedir. Ayaklara sahip olmayan bu kandillerin zemin kalınlıkları ile cidar kalınlıkları birbirine yakındır. Alt kısımları genelde düz olsa da az sayıda örnekte alt bölümün konkav olarak şekillendirildiği görülmektedir. ${ }^{9}$

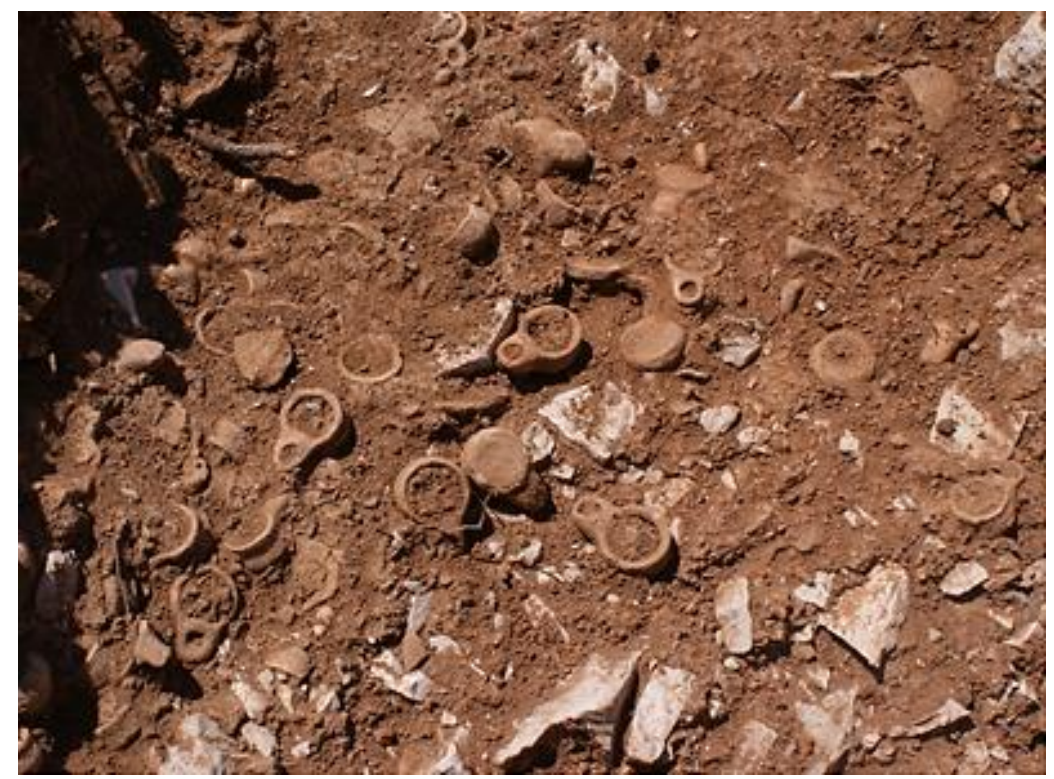

Fig. 2. Demeter Kutsal Alanı. Güney Nef içerisinde ele geçen kandiller

Altı düz olan örneklerde sıklıkla alt bölümde girdap biçimli izler karşımıza çıkmaktadır. Kapların göreceli olarak küçük ağızları vardır ve bunlar her zaman yuvarlak ya da üçgen formludur. Genellikle ağız kısımları gövdeye özensiz bir şekilde birleştirilmiştir. Yuvarlak ya da yuvarlağa yakın oval yanma deliklerine sahiptirler. Bunlarla ilgili en önemli detay bu kadar çok kandilin pratikte kullanıı kullanılmadıklarıdır. Yapılan gözlemlerde bunların çok nadir olarak yanma izleri karşımıza çıkmaktadır ${ }^{10}$. Ancak bu durum kandillerin sadece adanma aşamasında içine çok az yağ konularak yakılması nedeniyle, yanma süresince iz bırakamayacak kadar kısa zamanda sönmesi ile bağlantı olabilir.

Minyatür kandillerin dönem aralığı diğer buluntu gruplarının dönemsel yayılımına uymaktadır $^{11}$. Bunların çok büyük bir kısmı da diğer buluntuların genelinde olduğu gibi MÖ IV. yüzyıla ait olmalıdır. Bunlardan bir tanesinin alt kısmına Kaunos sikkeleri üzerinde görülen ve yapılan kazılarla varlığı da tespit edilen Baitylos’un grafitisi işlenmiştir. Bu örnek, özellikle buradaki kültün kutsal taş ile bağlantılı olabileceğini göstermesi açısından önemlidir ${ }^{12}$. Ayrıca kandillerin içlerinde nadir olarak altın yapraklarla ${ }^{13}$ (Fig. 5) ve daha yaygın olarak ise kırılmış kemik parçalarıyla adandıkları anlaşılmaktadır ${ }^{14}$ (Fig. 6).

9 Varkıvanç 1998, 91.

10 Varkıvanç 1998, 91.

11 Varkıvanç minyatür kandilleri formlarına göre yaklaşık MÖ 500-100 yılları arasına tarihlendirmekle birlikte bunların zaman içerisinde süreklilik gösteren bir form değişikliğine uğramadıklarını düşünmektedir.

12 Baitylos’un ele geçtiği kutsal alan ve Karia'daki kutsal taş kültü ile ilgili bilgi için bk. Diler 2000, 51-77; Diler 2017, 137-138. Ayrıca Kaunos'un genel olarak kültleri ve kült alanları için bk. Diler 2017-2, 165-194.

13 Kandillerle birlikte ele geçtiği için olasılıkla içlerine konarak adanmış olması gereken diğer altın yapraklar için bk. M. Bulba, Zur Rolle der Eliten im Demeterheiligtum in Kaunos (yayında).

14 Bulba 2010, Fig. 13. 
Yüksek sayılardaki minyatür kandillerin yanında bu kutsal alanda kazıların ilk olarak yürütüldüğü 1970'li yılların başlarında bazı büyük kandiller tespit edilmiştir. Teras'ın kuzey yönündeki depolama alanından ele geçen bu kandiller ile ilgili kısa bir bilgi yayınlanmıştır ${ }^{15}$. Bunlar Arkaik Dönem'den Erken Hellenistik Dönem içlerine kadar uzanmaktadır ${ }^{16}$. Tubitak Projesi kapsamında yürütülen son dönem kazılarında ise Hellenistik Dönem kandilleri, bir adet Roma Dönemi kandili ile üç adet kandil parçası tespit edilmiştir. Özellikle Roma Dönemi kandil ve kandil parçaları bu alanda şimdiye kadar tespit edilebilmiş üç sikke ile birlikte Roma Dönemi'ne işaret eden az sayıdaki buluntuları oluşturmaları bakımından ayrı bir öneme sahiptirler. Gerek Hellenistik gerekse Roma Dönemi kandilleri büyüklükleri ve uçlarındaki yanma izlerinden dolayı minyatür kandillerden farklı olarak aydınlatma amaçı olarak kullanılmış olmalıdırlar.

Formen und Maße kaunischer Miniaturlampen

\begin{tabular}{|c|c|c|c|}
\hline \multicolumn{1}{|c|}{$\begin{array}{c}\text { Lampen- } \\
\text { form }\end{array}$} & $\begin{array}{c}\text { H (cm) } \\
\text { min. - max. }\end{array}$ & $\begin{array}{c}\text { Dm }(\mathrm{cm}) \\
\text { min. - max. }\end{array}$ & $\begin{array}{c}\text { L }(\mathrm{cm}) \\
\text { min. - max. }\end{array}$ \\
\hline A & $1.7-2.1$ & $2.5-3.7$ & $3.9-5.0$ \\
\hline B & 1.85 & 3.5 & 4.45 \\
\hline C & $1.2-2.1$ & $1.2-3.1$ & $2.9-4.4$ \\
\hline D & $1.6-1.8$ & $3.2-3.4$ & $4.4-4.6$ \\
\hline E & $1.3-2.4$ & $2.7-3.2$ & $3.5-4.3$ \\
\hline F & $1.4-1.7$ & $2.5-3.8$ & $3.6-4.6$ \\
\hline G & $1.5-2.2$ & $2.3-3.2$ & $3.8-4.5$ \\
\hline H & $1.9-2.4$ & $2.9-3.8$ & $3.4-4.3$ \\
\hline I & $1.7-1.9$ & $2.8-3.4$ & $4.0-4.7$ \\
\hline J & $1.7-2.3$ & $3.5-4.9$ & $4.2-5.0$ \\
\hline K & $1.1-1.4$ & $2.9-3.2$ & $3.8-4.0$ \\
\hline L & $2.0-2.2$ & $3.0-3.2$ & $3.5-3.8$ \\
\hline M & $2.0-2.2$ & $3.9-4.0$ & $4.7-4.9$ \\
\hline N & $1.7-2.2$ & $3.4-4.2$ & $4.0-4.4$ \\
\hline O & $1.7-2.1$ & $4.0-4.9$ & $4.2-5.3$ \\
\hline P & $2.0-2.1$ & $3.3-3.7$ & $3.8-4.5$ \\
\hline Q & $1.9-2.0$ & $3.4-3.7$ & $4.2-4.4$ \\
\hline
\end{tabular}
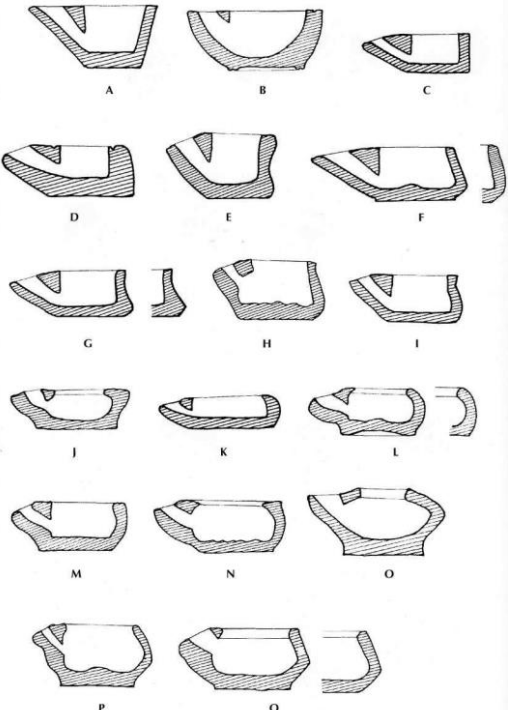

Fig. 3. Varkıvanç tarafından yayınlanan minyatür kandil formları ve ölçüleri

Minyatür kandiller dışında bir grup erken Hellenistik Dönem kandil ele geçmiştir (Fig. 7). Anadolu'da yaygın olarak karşımıza çıkan bu kandiller ${ }^{17}$ Atika örnekleri ile de yakından benzeşmektedir. Üzerlerinde kırmızı ve siyah astar boya seçilebilmektedir. Batı Anadolu'da birçok merkezde karşımıza çıkan bu kandiller minyatür kandillerin aksine olasılıkla ithaldirler. Hamur renkleri ve özellikleri ile işçilikleri minyatür kandillere göre daha yüksektir. Bununla birlikte hamur analizleri henüz yapılmadığı için bunların ithal veya yerel üretim eserler olup olmadıkları henüz belirsizdir.

Atika tipli kandillerin yanında birisi sağlam diğerleri ise parçalar halinde olmak üzere 5 adet Roma Dönemi kandil ele geçmiştir (Fig. 8). Sağlam olarak ele geçen örnek olasılıkla MS I. yüzyılın ikinci yarısı ya da II. yüzyıla aittir ${ }^{18}$. Parçalar halinde ele geçen örneklerin tarihlendirilmeleri

15 Öğün 1973, 163-167.

16 Öğün 1974, 133-136

17 Howland 1958, 99, tip 32, lev. 41, nos. 425-432; Scheibler 1976, 111-113 no. 279. Erken Hellenistik; Kassab-Tezgör - Sezer 1995, nos. 176-177, 185. MÖ III. yüzyılın ilk yarısı; Bussière - Lindros-Wohl, 16, No: 13-14. MÖ III. yüzyılın ilk yarısı.

18 Kalp burunlu kandiller olarak adlandırılan bu grubun genel özellikleri, kaynakçası ve karşılaştırma örnekleri için bk. Öz 2018, 561 vd. 
mümkün olmasa da sağlam örnek ile aynı ya da yakın bir dönemde üretilmiş olmaları mümkündür. Az sayıda Roma Dönemi sikkesi ${ }^{19}$ ile bu döneme ait sınırlı sayıdaki buluntunun kült işlevlerindeki fonksiyonunu tespit edebilmek oldukça güçtür. Adak bırakma geleneğinin neredeyse tamamen sona erdiği bu dönemde, söz konusu kandillerin gece törenleri için mi yoksa sadece adak için mi bırakıldığı belirsizdir. Ancak diğer kandil gruplarıyla karışık olarak ele geçmeleri bunların tesadüfen bu alanda olmadıklarını ortaya koyar.

Kandiller içerisinde iki adet birden fazla burnu olan minyatür kandil de bulunmuştur ve bu haliyle diğer minyatür kandillerden ayrılmaktadırlar (Fig. 9). Sayıları çok az olduğu için herhangi bir yaygın kullanım geleneğinden bahsetmek mümkün olmasa da bunların aşağıda bahsedilecek olan kandil kernoslarıyla benzer bir işleve sahip olduğunu düşünülebilir.

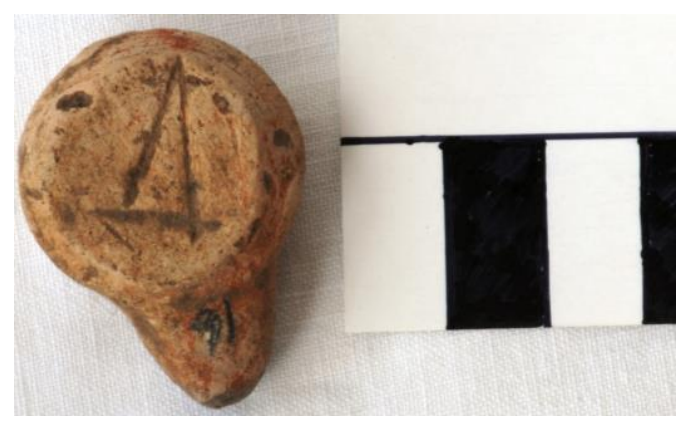

Fig. 4. Alt kısmına Baitylos çizimi bulunan minyatür kandil

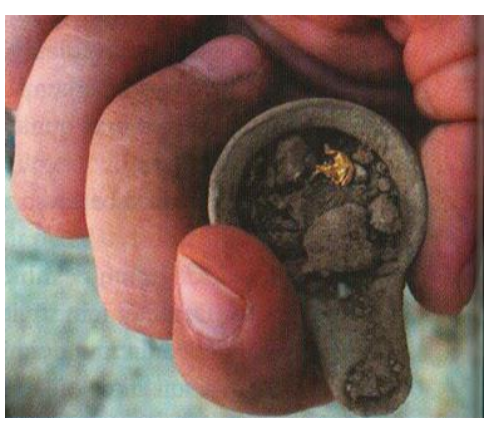

Fig. 5. İçerisinde altın yaprak ele geçen minyatür kandil

Kandiller genel olarak Demeter Kutsal Alanları'nın tipik buluntu gruplarından birini oluşturmakta ve sayıca fazla oranda ele geçmektedirler ${ }^{20}$. Bununla birlikte Kaunos gibi küçük bir kentin Demeter Kutsal Alanı'nda bu kadar fazla sayıda ele geçmesi dikkat çekicidir. Şimdiye kadar ele geçen minyatür kandillerin uçlarında yukarıda bahsedildiği gibi yanma izleri çok ender olarak karşımıza çıktığı için bunların sembolik olarak ve yakılmadan bırakılmış olma ihtimalleri güçlü bir olasılıktır. Haznelerinin küçüklüğü nedeniyle aydınlatma amacı ile kullanılmamış olmaları gerekmektedir. Bu durum minyatür kandillerin adak olarak bırakıldığı diğer buluntu merkezleri için de geçerli olmalıdır ${ }^{21}$. Çok az merkezde yakılarak bırakıldığı tespit edilen kandil buluntusu yayınlanmıştır ${ }^{22}$.

Aydınlık ve karanlık tanımlamaları (gece ve gündüz) daha erken dönemlerden itibaren iyi ve kötüyü sembolize etmede kullanılmışır ${ }^{23}$. Demeter'in en yaygın bayramı olan Thesmophoria şenlikleri üç gün boyunca kutlandığı için gece kutlamalarına yönelik yazılı belgelerin yanında çok sayıda ele geçmeleri nedeniyle kandillerin gece törenlerinde kullanıldığı kabul edilmektedir ${ }^{24}$.

19 Sikkeler Z. Çizmeli-Öğün tarafından yayına hazırlanmaktadır. Çizmeli-Öğün'ün bildirdiğine göre ele geçen sikkelerin 335'i Klasik Dönem'e, 64'ü Hellenistik Dönem'e ve sadece 3 tanesi Roma Dönemi'ne aittir.

20 Demeter Kutsal Alanları́nda ele geçen kandil buluntularının listesi için bk. Karatas 2015, 441-442.

21 Beregovoi 4 olarak literatüre geçen Karadeniz'in kuzeyindeki Patraios antik kenti yakınlarında bulunan Demeter Kutsal Alanı'nda ele geçen çok sayıda kandilin sembolik olarak bırakıldıkları yağ haznesi ile ağız kısımları arasında bağlantı dahi olmamasından kesin olarak anlaşılmaktadır. Bu kutsal alanda aynı zamanda Kaunos'taki çukurlar gibi içlerinde kül ve kemik olan birçok sunu çukuru tespit edilmiştir, bk. Zavoikin -Zhuravlev 2013, 155 vd.

22 Adanmadan önce kullanıldığı anlaşılan çok az kandil literatürde anılmıştır. Örneğin Mytilene'de adanan kandillerin tümü adanmadan önce kullanılmıştır, bk. Cronkite 1997, 56.

23 Hermanns 2004, 20.

24 Parisinou 2000, 38. Thesmophoria ve Haloa törenleri için: 126-130, Demeter kültlerinde genel kullanımları 
Milas'tan ele geçen MÖ III. yüzyıla ait bir yazıt, kadınlar festivali için düzenlenen törenlerde gece kandil kullanımıyla ilgili kurallardan bahsetmektedir. Yazıtta Demeter'in adı geçmemekle birlikte burada Thesmophoria şenliklerinden bahsedilmiş olması güçlü bir olasılıktır ${ }^{25}$. Demeter kültlerinde çok sayıda kandil adanmasının nedenini Schipporeit, ele geçen kandil buluntuların kadınların ev işleriyle ilgilerinden dolayı kadınlar tarafından Demeter'e adanmış olması gerektiği şeklinde açıklamaktadır ${ }^{26}$. Bununla birlikte özellikle üç gün boyunca kutlanan Thesmophoria şenliklerinde gece kutsal mekânda kalındığı için aydınlanma amaçlı olarak kandil ve/veya meşale kullanıımış olması gereklidir. Kaunos'ta meşale kullanımına yönelik bir buluntu olmadığı gibi, bazı Demeter Kutsal Alanları́nda karşımıza çıkan meşale taşıyan figürinler de görülmez. Khthonik özelliğe sahip olduğu anlaşılan Kaunos'taki Demeter Kutsal Alanı'na bırakılan bu kandiller olasıııkla ruhların öteki dünyanın karanlığında yollarını bulmalarını umut etmek amacıyla sembolik olarak bırakılmışlardır.

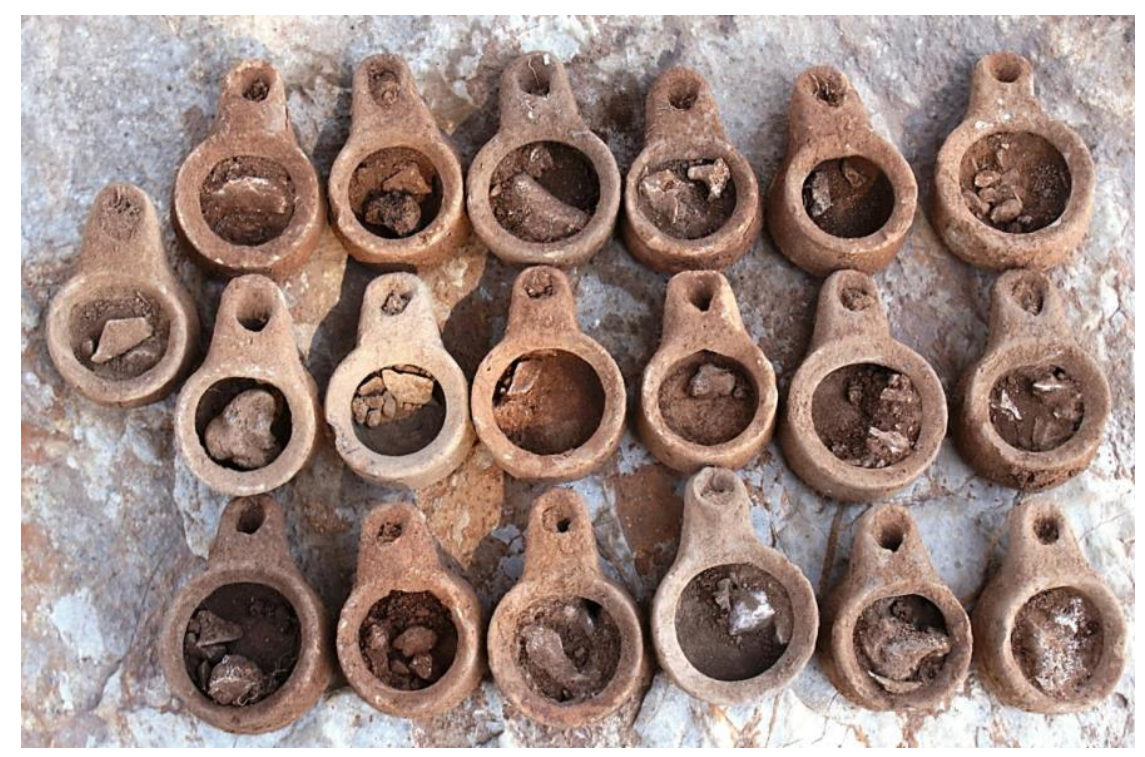

Fig. 6. İçlerinde kemik kırıkları ile adanan kandiller

Kaunos'ta ele geçen kandil sayısının bu kadar fazla olması öncelikle kült için çok önemli bir sembolik anlama sahip olduklarını göstermektedir. Bu minyatür kandillerin aydınlatma amacıyla bırakılmış olmaları çok zayıf bir ihtimal olduğundan bu alanda yapılan törenlerin gece gerçekleştiğini söylemek zordur. Ele geçen büyük boyutlu kandil sayısı bu alanın aydınlatılmasına hizmet edebilecek kapasiteden çok uzaktır. Olasılıkla bu kandiller de aynı minyatür kandiller gibi adak olarak, ancak onların aksine kullanıldıktan sonra alana bırakılmışlardır. Bunların minyatür kandiller ile birlikte ele geçmesi, büyük ve küçük kandillerin aynı şekilde adandıklarına işaret ediyor olmalıdır.

Bunların sayısı sadece Kaunos'ta yaşayan insanların bırakabileceğinden çok daha fazladır. Burası özellikle Hekatomnidler Dönemi'nde kent üstü bir kutsal alan hüviyetine sahip olmuş ol-

için 136-150; Luni 2005, 66.

25 Karatas 2015, 471 ve 658 vd. Demeter dışında Apollon, Eros ve Helios gibi tanrılara da kandil adandığını bildirmektedir. Ayrıca Hellström Karataş'a Labraunda Zeus kutsal alanında çok sayıda kandil ele geçtiğini, ancak Zeus'a ait olabilecek figürin tespit edilemediğini sözlü olarak bildirmiştir (Karatas 2015, 690).

26 Schipporeit 2013, 220 vd. Buna karşın Karatas 2015, 659, tüm Demeter kutsal alanlarında kandil ele geçmemesinden hareket ederek kandillerin birçok tanrıya değişik amaçlarla adanmış olması gerektiğini bildirir. 
malıdır. Karia'da Halikarnassos'ta ${ }^{27}$, lasos'ta ${ }^{28}$, Knidos'ta $^{29}$, yakın coğrafya içerisinde ise Rodos'ta $(\text { kent })^{30}$ ve Lindos'ta ${ }^{31}$ çok sayıda kandil ele geçmiştir. Bunun yanında Batı Anadolu'daki ve Ege adalarındaki Demeter Kutsal Alanları'nda da çok sayıda kandil adak olarak bırakılmıştır ${ }^{32}$. Ancak bu merkezlerdeki kandil sayıları nispeten fazla olan sayılarına rağmen yoğunluk bakımından Kaunos'takilerle karşılaştırılamayacak sayıdadırlar. Karatas'ın da vurguladığı gibi erkek figürinlerle birlikte bol kandil adanması Karia'daki Demeter Kutsal Alanları'nda genel özellik olarak karşımıza çıkmaktadır ve Priene örneğinde olduğu gibi bunların diğer merkezlerde Karia etkisi ile adandığı söylenebilir ${ }^{33}$. Ancak ilginç olan Miletos'ta Humaytepe'de yer alan Demeter Kutsal Alanı'nda karşımıza çıkmayıp Athena Kutsal Alanı yakınındaki Demeter Kutsal Alanı'nda ele geçmeleridir ${ }^{34}$. İonia'daki merkezlerde ise kandil buluntuları daha seyrek olarak karşımıza çıkmaktadır ve bu durum bölgesel özelliklerle açıklanabilir.
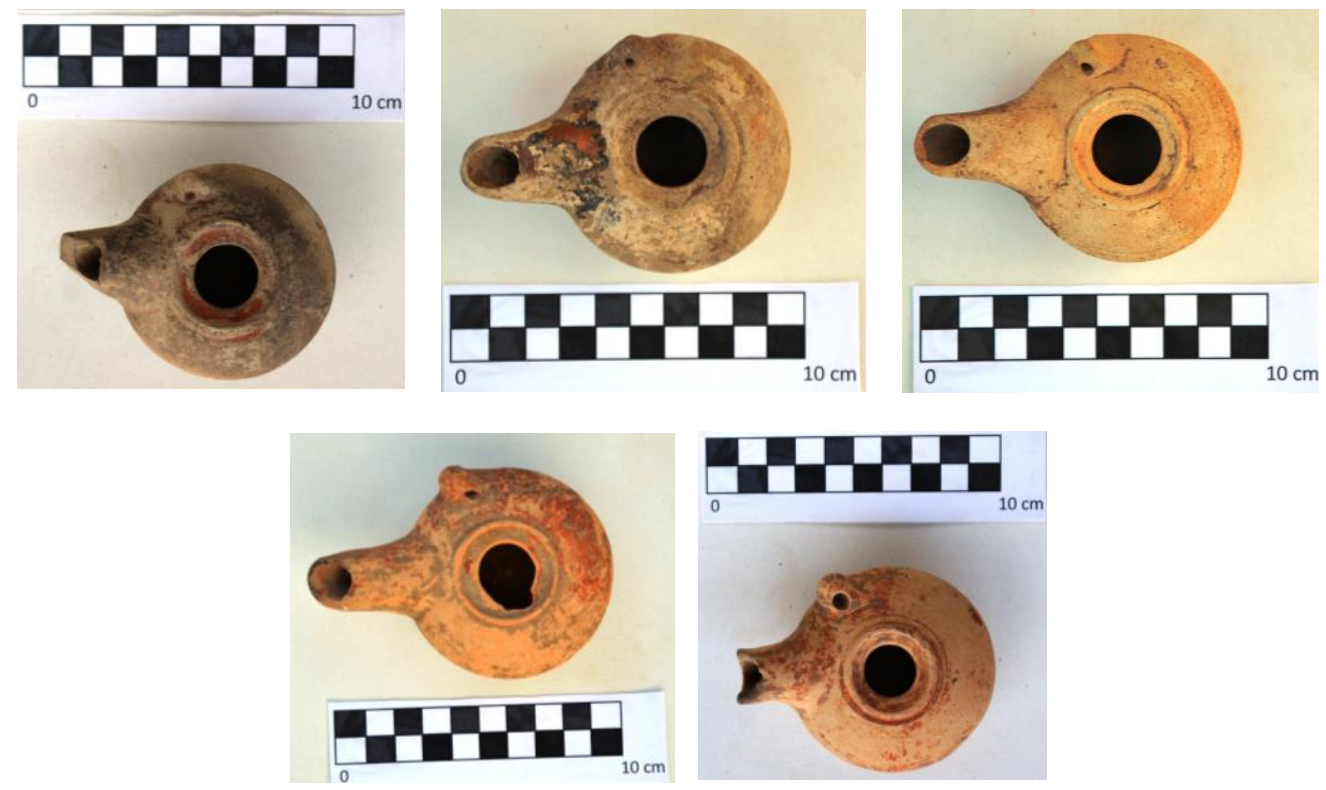

Fig. 7. Hellenistik Dönem Kandilleri

Kandiller sadece Demeter'e özgü kutsal alanlarda karşımıza çıkmaz. Demeter insanlara yiyecek sağlarken, Dionysos ise aynı zamanda üzüm suyu yoluyla onları dertlerinden uzaklaştırmakta, uyku vermektedir ${ }^{35}$. Demeter gibi Dionysos için de gece şenlikleri düzenlenmektedir. Bu şenliklerde kadınlar ve erkekler tanrı ile bir olmak için şarap tulumları ile ve thyrsos çubuklarıyla açık alanlara çıkıyordu. Ancak Kaunos'taki kutsal alanın genel karakterinin khthonik özellikler gösterdiği düşünülürse buradaki kandillerin Dionysos ile bu törenler kapsamında özdeşleştirilmesi zordur. Bunun yanında Artemis ${ }^{36}$ ve Athena $^{37}$ ve Aphrodite ${ }^{38}$ kültlerinde de kandillere

27 Newton $1865,72$.

28 Levi 1969, 119; Johannowski 1985, 55.

29 Newton - Pullan 1863, 393 vd.; Newton 1865, 185-186.

30 Zervoudaki 1988, 129.

31 Blinkenberg 1931, nos: 2543-2564.

32 Karatas 2015, 657 (buluntu merkezleri ve yaklaşık ele geçen kandil sayıları ile birlikte).

33 Karatas 2015, 238 (Priene), 293 vd. (Miletos).

34 Karataş 2015, 657 vd.

35 Giebel 2000, 55 dn. 49.

36 Minyatür Hydrialar ve kandiller Artemision'daki altarın yanında ele geçmiştir ve Forstenpointner bunların Thesmophoria törenlerinde kullanıldığını düşünmektedir: Forstenpointner 2001, 59 dn. 76. 
rastlanmaktadır. Özellikle Miletos'taki Aphrodite Kutsal Alanı'ndaki buluntu durumu Kaunos örneği ile kandillerin formları hariç benzeşmektedir. Burada binlerce kandil parçası kutsal alanın içerisinde ve çevresinde ele geçmiş ve sadece bir özet şeklinde yayınlanmışlardır ${ }^{39}$. Bu alanda binlerce kandil parçası yanında, yuvarlak biçimli ocak, çok sayıda hayvan kemiği (içlerinde domuz tespit edilmemiştir), kaya boşluklarının atık depolama alanı olarak kullanılması gibi özellikler bakımından Kaunos ile benzeşmektedir.
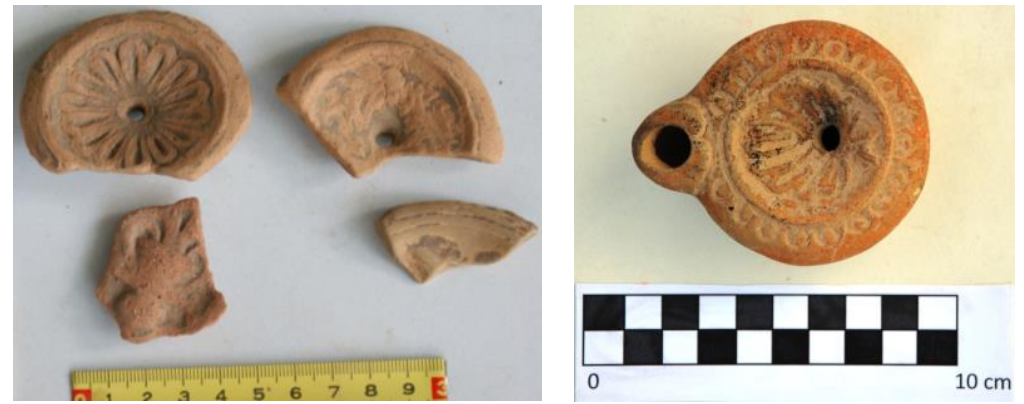

Fig. 8. Roma Dönemi kandil ve kandil parçaları

Hinz, Demeter ve Persephone'nin Akragas'taki Satuario Ctonio ve San Bigio kutsal alanlarında ele geçen kandillerin tanrıçaların khthonik özellikleriyle ilişkili olabileceklerini düşünmektedir ${ }^{40}$. Her ne kadar Schipporeit kandillerin Ephesos Artemis ve Miletos Aphrodite gibi khthonik özellikleri hemen hiç olmadığını düşündüğü kutsal alanlarda da ele geçmesinden dolayı zor bir ihtimal olduğunu ileri sürse de ${ }^{41}$ Kaunos'taki çok sayıdaki örnekte içlerinde domuz kemikleri ile birlikte adanmaları ve yine yeraltı kültüyle yakından bağlantıı olması gereken altın yaprakların bazı örneklerinden ele geçmesi en azından Kaunos örneklerinden hareketle kandillerin tanrıçanın khthonik özelliğiyle uyuşmaktadır.

\section{Kandil Kernosları}

Kaunos Demeter Kutsal Alanı'nda çok sayıda kernos ele geçmiştir $^{42}$. Bunların büyük çoğunluğu hydria kernosları tipine

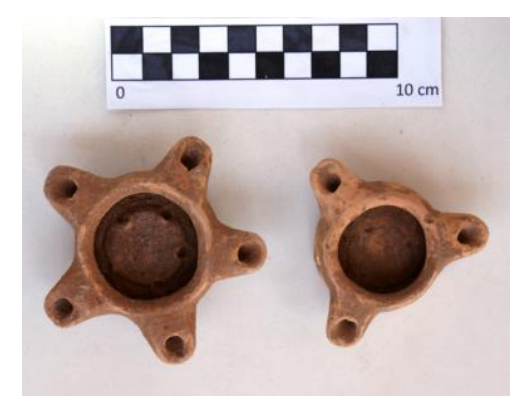

Fig. 9. Çoklu burnu olan kandiller aittir. Çok daha ender olarak karşımıza çıkan kandil kernoslarını iki tipe ayırmak mümkündür. Bunlardan birincisi minyatür kandillerin yan yana dizilmesiyle oluşan tiptir (Fig. 10). Kernos üzerindeki kandil sayıları ve tipleri değişkendir. Bugüne kadar sadece tek örnekle temsil edilen ikinci tipte açık olan ortak bir yağ haznesi bulunmakta olup çok sayıda kandil burnu dış kısma eklenmiştir ${ }^{43}$ (Fig. 11). Çok sayıda burnu olan kandiller MÖ geç V. yüzyıldan itibaren karşımıza çıkarlar ve özellikle kült alanlarında kapalı mekânların aydınlatılması için gerekli ışı̆̆ı sağlama

37 Parisinou 2000, 151 vd. (Artemis); 156 vd. (Athena).

38 Senff 2003, 18 dn. 34: Aphrodite kutsal alanlarında yapılan gece kutlamalarıyla ilgili literatur ile birlikte; Nilsson 1950, 105-106.

39 Selesnow 1997, 137 vd. Bu alanda ele geçen kandillerin yaklaşık \%70'i Fenike-Punik tipi kandillerdir ve bu alan dışında o zamana kadar Miletos'tan örnekleri bilinmediği bildirilmektedir.

40 Hinz 1998, 49 dn. 321-323.

41 Schipporeit 2013, 221. Schipporeit bu durumu daha çok evlerde kadınların kandillerle daha fazla uğraşması ile ilişkilendirmek istemektedir.

42 Doyran 2008, 149 vd; 2017, 59-63; Bulba 2018 (hydria kernosları).

43 Doyran 2017, 63 Fig. 3. 
amaçlı olarak gittikçe artan yoğunlukta kullanılmışlardır ${ }^{44}$.

Hydria kernosları hydrialarla ortak bir adak grubunu oluştururken kandil kernosları da kernoslar ile ortak adanma amacına hizmet etmiş olmalıdırlar. Bununla birlikte hydrialara nazaran çok yoğun karşımıza çıkan hydria kernosuna karşın çok yüksek sayıda ele geçen kandile oranla kandil kernosunun çok nadir görülmesinin nedenini açıklamak zordur. Yağ haznesi ortak olan kandil kernosu işçilik ve boya kalitesiyle gerek diğer kandil gerekse hydria kernoslarının aksine daha niteliklidir ve bu yönüyle diğer tüm kernoslardan ayrışmaktadır. Hydria kernoslarının aksine kandil kernosları başüzerinde değil elde taşınmış olmaları gerekmektedir.
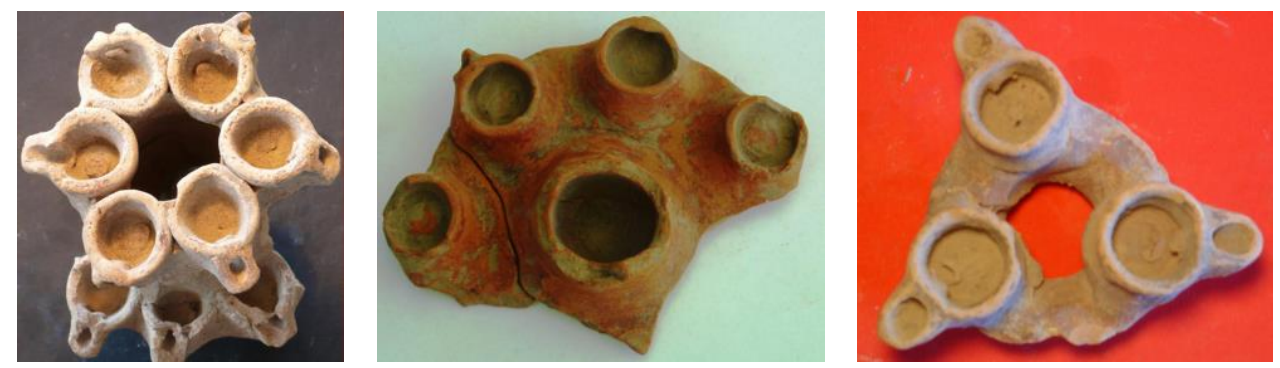

Fig. 10. Minyatür kandillerden oluşan kernoslar

Kernosların Kaunos'taki Demeter Kutsal Alanı'nın geleneksel sunulardan biri olduğu kabul edilebilir. Bunlar Anadolu ve diğer Demeter kutsal alanlarının bazılarında görülürken bazılarında ise hiç karşımıza çıkmazlar. Bu nedenle Demeter Kutsal Alanları'nın tipik adak buluntuları olduğunu söylemek zordur ${ }^{45}$. Kandil kernoslarının tarihlendirilmesi buluntuların karışık olması nedeniyle zordur, bununla birlikte Demeter Kutsal Alanı'nın en parlak zamanlarını yaşadığı Maussollos dönemine ait olmaları güçlü bir olasılıktır.

\section{Sonuç ve Değerlendirme}

Kaunos Demeter Kutsal Alanı'nda ele geçen minyatür kandillerin sayısı buradaki törenlerin canlılı̆ını ve katılımcı sayısının yüksekliğini ortaya koymaktadır. Yeni ele geçen buluntularla az sayıda büyük kandilin de adandığı, ancak bunların törenlerin gece kutlamalarına yetecek kadar aydınlatma kapasitesine sahip olmadığı netleşmiştir. Gerek minyatür kandillerin, gerekse kandil kernoslarının bir defalığına ve sembolik olarak bırakıldıkları ve törenlerin tamamlanmasından sonra atık depolama alanlarına atıldıkları anlaşılmaktadır.

44 Hermanns 2004, 22-23. Yazarın yayınlamış olduğu Selinunt'daki Demeter Malophoros Kutsal Alanı'ndan ele geçen kandil kernosları kısmen Kaunos'taki Demeter Kutsal Alanı'ndan bulunan kandil kernoslarını anımsatmaktadır (lev.4, Fig. 9).

45 Kernosların buluntu merkezleri için bk. Karatas 2015, tablo 5.6. 


\section{BİBLIYOGRAFYA}

Blinkenberg 1931

Bulba 2010

Bulba 2018

Bulba 2019

Bulba 2019/2

Bussière - Lindros - Wohl 2017

J. Bussière, B. Lindros - Wohl, Ancient Lamps in the J. Paul Getty Museum. Los Angeles 2017.

Cronkite 1997

Diler 2000

Diler 2017

Diler 2017-2

Doyran 2008

Doyran 2017

Forstenpointner 2001

Giebel 2000

Hermanns 2004

Hinz 1998

Howland 1958

Johannowski 1985

Karatas 2015

Kassab-Tezgör - Sezer 1995

D. Kassab-Tezgör - T. Sezer, Istanbul Arkeoloji Müzeleri Pişmiş Toprak Kandiller Kataloğu. İstanbul 1995.

Levi 1969

Luni 2005

Newton 1865

Newton - Pullan 1863

Ch. Blinkenberg, Lindos. Fouilles de L'Acropole 1902-1914. I - Les Petits Objects. Berlin 1931.

M. Bulba, "Bothroi in Küçükkale in Kaunos". Belleten 271 (2010) 649-667.

M. Bulba, "Demeter Kutsal Alanı: Seramik Buluntular". MJH VIII/2 (2018) 159-179.

M. Bulba, "Demeter Kutsal Alanı: Terrakotta Buluntular". Cedrus VII (2019) Baskıda.

M. Bulba, "Zur Rolle der Eliten im Demeterheiligtum in Kaunos". Anodos 13-14 (2013-1014)(baskıda).

S. M. Cronkite, The Sanctuary of Demeter at Mytilene: A Diachronik and Contextual Study. Yayımlanmamış Doktora Tezi. University College. Londra 1997. A. Diler, "Sacred Stone Cult in Caria". Ed. C. Işık, Studien zur Religion und Kultur Kleinasiens und des ägäischen Bereichs. Festschirft für Baki Öğün zum 75. Geburtstag. AMS Band 39. Bonn (2000) 53-77.

A. Diler, "Bir Kültür Bölgesi Olarak KBID/Kaunos ve Karia Kimliğindeki Yeri". Eds. A. Diler, S. Özen - U. Çörtük vd. 50 Yılında Kaunos. İzmir (2017) 136-154.

A. Diler, "Kaunos/Kbid Tanrı Kültleri ve Kült Alanları Üzerine Bazı Notlar". Eds. M. Doyran, B. Özen-Kleine, U. Çörtük - S. Özen, Uluslararası "Anadolu'da Demeter ve Diğer Ana Tanrıça Kültleri" Sempozyumu, 25-28 Haziran 2014, Kaunos Kazıevi. İzmir (2017) 165-194.

M. Doyran, "Demeter Cult at Caunos: Kernoi". Ed. M. Novotná, Cult and Sanctuary through the Ages: From the Bronze Age to the Late Antiquity. Casta Papiernicka, 16-19 November 2007. Tr nava (2008) 149-154.

M. Doyran, "Kaunos Kernosları". Eds. A. Diler, S. Özen - U. Çörtük vd. 50 Yılında Kaunos. İzmir (2017) 59-65.

G. Forstenpointner, "Demeter im Artemision? Archäologische Überlegungen zu den Schweineknochenfunde aus dem Artemission". Ed. U. Muss, Der Kosmos der Artemis von Ephesos. Viyana (2001) 49-71.

M. Giebel, Das Geheimnis der Mysterien. Düsseldorf - Zürih 2000.

M. H. Hermanns, Licht und Lampen im westgriechischen Alltag. Rahden 2004.

V. Hinz, Der Kult von Demeter und Kore auf Sizilien und in der Magna Graecia. Wiesbaden 1998.

R. H. Howland, Greek Lamps and their Survivals. The Athenian Agora. Band IV. Princeton 1958.

W. Johannowsky, "Appunti sul Santuario di Demeter e Kore". Studi su lasos di Caria. Venticinque anni di scavi della Missione Archeologica Italiana, Bollettino d'Arte, Suppl. BDA 31/32, 1985. Roma (1987) 55-58.

A. M. S. Karatas, The Sanctuaries of Demeter in Western Asia Minor and on the Islands Off the Coast. Yayımlanmamış Doktora Tezi. University of Bristol. Bristol 2015.

D. Levi, "La mission archéologique italienne de lasos". TürkAD 17 (1969) 117121.

M. Luni, "Le nouveau sanctuaire de Déméter à Cyrène et découvertes récentes". CRAI 149 (2005) 61-86.

C. T. Newton, Travels and discoveries in the Levant. Londra 1865.

N. C. Newton - R. P. Pullan, "A History of Discoveries at Halicarnassus". Cnidus and Branchidae, vol. II, part II. Londra 1863. 
Nilsson 1950

Öğün 1971

Öğün 1972

Öz 2018

Parisinou 2000

Scheibler 1976

Schipporeit 2013

Selesnow 1997

Senff 2003

Varkıvanç 1998

Zavoikin - Zhuravlev 2013

Zäh 2001

Zäh 2001/2

Zervoudaki 1988
M. P. Nilsson, "Lampen und Kerzen im Kult der Antike". Opuscula Archaeologica VI (1950) 96-111.

B. Öğün, "Kaunos - 1971". TürkAD 20.1 (1973) 163-167.

B. Öğün, "Kaunos Kazıları 1972". TürkAD 21.1 (1974) 133-136.

C. Öz, "Silifke Müzesi'nde Bulunan Pişmiş Toprak Kandiller". Eds. T. Kahya, A. Özdizbay, N. Tüner Önen - M. Wilson, Uluslararası Genç Bilimciler Buluşması II. Anadolu Akdenizi Sempozyumu. 04-07 Kasım 2015, Antalya. İstanbul (2018) 553584

E. Parisinou, The Light of the Gods: The Role of Light in Archaic and Classical Greek Cult. Londra 2000.

I. Scheibler, Griechische Lampen. Kerameikos Band. XI. Berlin 1976.

S. T. Schipporeit, Kulte und Heiligtümer der Demeter und Kore in Ionien. İstanbul 2013.

W. Selesnow, "Ausgewählte Lampen von Kalabak-und Zeytintepe". AA (1997) 137-143.

R. Senff, "Das Aphroditeheiligtum von Milet". Ed. G. Heedemann, Neue Forschungen zur Religiongeschichte Kleinasiens. Feschtschrift für E. Schwertheim, AMS 49. Bonn (2003) 11-25.

B. Varkıvanç, "Miniaturlampen aus dem Demeterheiligtum in Kaunos". Adalya 3 (1998) 88-96.

A. Zavoikin - D. Zhuravlev, "Lamps from a Sanctuary of Eleusinian Godesses "Beregovoi - 4"”. Ancient Civilizations from Scythia to Siberia 19 (2013) 155-216. A. Zäh, "Das spätantike und byzantinische Kaunos". IstMitt 51 (2001) 403-413.

A. Zäh, "Die Kirchen von Kaunos". TürkAED 2 (2001) 111-116.

E. Zervoudaki, "Vorläufiger Bericht über die Terrakotten aus dem Demeter-Heiligtum der Stadt Rhodos". Eds. S. Dietz - I. Papachristodoulou, Archaeology in Dodecanese, Copenhagen April 7th to 9th, 1986. Kopenhag (1988) 129-137. 